\title{
Effect of process parameters and heat treatments on delta-phase precipitation in directed energy deposited alloy 718
}

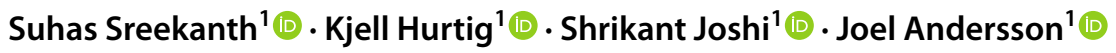

Received: 26 September 2021 / Accepted: 9 January 2022 / Published online: 24 January 2022

(c) The Author(s) 2022, corrected publication 2022

\begin{abstract}
This article outlines a detailed study of solution treatments and delta precipitation treatments carried out on laser-directed energy deposited (DED) alloy 718 specimens. Two different sets of DED process parameters were used in high and low energy conditions that yield different microstructural features to study the effect of process parameters on delta precipitation. These two conditions were subjected to solution treatment at $1010^{\circ} \mathrm{C}$ and $1050{ }^{\circ} \mathrm{C}$ each for $1 \mathrm{~h}$, which improved homogeneity and altered grain texture with introduction of annealing twins. The as-built and solution-treated specimens served as the initial reference condition for subsequent delta processing treatments (DPT) performed at three temperatures of $850{ }^{\circ} \mathrm{C}$, $900{ }^{\circ} \mathrm{C}$, and $950{ }^{\circ} \mathrm{C}$ to study the effect of short- and long-term exposures ranging from 1 to $48 \mathrm{~h}$. When as-built specimens were subjected to DPT, interdendritic delta precipitates were observed at Nb-rich regions. In contrast, solution-treated specimens under short-term exposure to DPT resulted in intergranular delta phase precipitates whereas under long-term exposures to DPT yielded predominantly intragranular delta precipitates, which grew denser and longer with increased time of treatment. For longer exposure times of 24 and $48 \mathrm{~h}$, a continuous film of intergranular delta phase was noticed. The morphology, location, and volume fraction of delta phase precipitates studied in this research are imperative for designing the performance of alloy 718 built by DED process.
\end{abstract}

Keywords Laser-directed energy deposition $\cdot$ Heat treatment $\cdot$ Alloy $718 \cdot$ Delta-phase precipitation

\section{Introduction}

Alloy 718 is a nickel, iron-based superalloy which is primarily used in aerospace, space, petrochemical, and oil and gas industries due to its superior high-temperature properties and corrosion resistance, with service temperatures varying between -200 and $650{ }^{\circ} \mathrm{C}$. The alloy mainly derives its strength from precipitation of primarily coherent gamma double prime $\left(\gamma^{\prime \prime}-\mathrm{Ni}_{3} \mathrm{Nb}\right.$ body-centred tetragonal) and gamma prime $\left(\gamma^{\prime}-\mathrm{Ni}_{3} \mathrm{Al}\right.$, Ti face-centred cubic) phases,

Suhas Sreekanth

suhas.sreekanth@hv.se

Kjell Hurtig

kjell.hurtig@hv.se

Shrikant Joshi

Shrikant.joshi@hv.se

Joel Andersson

joel.andersson@hv.se

1 Department of Engineering Science, University West, Gustava Melins gata 2, 46132 Trollhättan, Sweden whereas controlled precipitation of delta phase $\left(\delta-\mathrm{Ni}_{3} \mathrm{Nb}\right.$ orthorhombic) is known to induce grain stability in wrought form of alloy 718 [1]. The metastable $\gamma^{\prime \prime}$-phase transforms into a more stable $\delta$-phase at temperatures exceeding $750{ }^{\circ} \mathrm{C}$ [2].

$\delta$-precipitation occurs in alloy 718 between the temperature range of 800 and $1000{ }^{\circ} \mathrm{C}$, and the corresponding thermal treatment designed to achieve $\delta$-phase saturation in the alloy is sometimes called delta processing treatment (DPT) [3]. Based on the location of precipitation, $\delta$-phase can be distinguished as intergranular- or intragranular- $\delta$. Morphologically, intergranular- $\delta$ appears as discrete globular or blocky particles, whereas the intragranular- $\delta$ appears as acicular precipitates [4]. During long-term precipitation treatment, a continuous long-striped intergranular $\delta$-phase film forms at the grain boundaries (GBs) [5]. Many material properties of importance in aerospace applications, such as tensile strength, creep resistance, fatigue strength, and ductility, depend on precipitation strengthening and grain stability, which in turn is affected by morphology, distribution, and volume fraction $\left(\mathrm{V}_{\mathrm{f}}\right)$ of $\delta$-phase in alloy 718 . Alloy 718 
components often undergo repetitive repair and refurbishing activities during their lifetime, which exposes the material to DPT temperatures for longer times than actual heat treatments $[6,7]$. Therefore, in order to simulate these effects, long-term exposure of material subjected to DPT protocols (up to $48 \mathrm{~h}$ ) is studied in the present work.

The evolution study of $\delta$-phase by Anderson et al. [8] revealed that the interplay between the amount of inter- and intragranular precipitation of $\delta$-phase can affect formability of alloy 718 . Uniaxial tensile testing showed increase in both yield and tensile strength for wrought specimens subjected to solution treatment at $1100{ }^{\circ} \mathrm{C} /$ water quenched (WQ), and DPT performed at $900{ }^{\circ} \mathrm{C} / 8 \mathrm{~h} / \mathrm{WQ}$ as the mode of $\delta$-precipitation was predominantly intergranular [4]. Furthermore, increasing DPT time resulted in loss of strength and ductility, which was attributed to the precipitation of intragranular acicular $\delta$-plates. A research by Kuo et al. [9] claimed that the morphology, amount, and orientation of $\delta$-phase determined the creep and stress-rupture properties of alloy 718. The alloy subjected to direct aging after $1095^{\circ} \mathrm{C} / 1 \mathrm{~h}$ solution treatment showed superior stress rupture life (SRL) of $331 \mathrm{~h}$ and ductility (El.) of $5.4 \%$ compared to those that underwent an intermediate DPT at $955^{\circ} \mathrm{C}$ for $1 \mathrm{~h}$ (SRL-160 h, El.-1.15\%) and $3.5 \mathrm{~h}$ (SRL197 h, El.-1.49\%), respectively. Contrarily, Cai et al. [10] showed that a minimum of $0.6 \%$ wt. $\delta$-phase is needed for alloy 718 to resist notch rupture, when notches are present as features added as a part of basic design or occur during service of components. However, the tensile strength and ductility were not affected when $\delta$-phase is present in low amount $\left(\underline{V}_{\mathrm{f}}=0.6-1.3 \%\right)$ [11]. The creep life and resistance to crack propagation behavior were both affected by the presence of $\delta$-phase precipitates as per the work performed by $\mathrm{Li}$ et al. [12]. The authors argued that intergranular crack propagation is hindered by the presence of globular delta precipitates which form a $\gamma^{\prime \prime} / \gamma^{\prime}$ denuded zone resulting in regions having more plasticity. Low-cycle fatigue properties showed no direct correlation with the amount of $\delta$-phase $\mathrm{V}_{\mathrm{f}}$ in wrought alloys [13], although the bimodal distribution of grains that resulted due to uneven $\delta$-precipitation decreased the fatigue life. The presence of higher amount of $\delta$-phase resulted in a microstructure of non-recrystallized grains having large $V_{f}$ of $\delta$-phase that decreases the loadbearing capability. In summary, short intergranular $\delta$-phase precipitates have been reported to be beneficial in enhancing the tensile strength, ductility, creep life, stress-rupture, and notch-rupture properties of alloy 718 . On the other hand, the intragranular $\delta$-phase enhances the tensile strength but depletes the ductility of alloy 718 and is of no consequence in affecting the fatigue and creep resistance.

The literature reviewed above shows the importance of $\delta$-phase precipitation in alloy 718 . However, these studies pertain to alloy 718 manufactured by conventional wrought or forged routes, which is essentially different from additive manufacturing $[14,15]$. In the present work, laser-directed energy deposited (DED) specimens produced by varying process parameters are subjected to various heat treatment protocols to study their effect on $\delta$-precipitation. Due to the differences in solidification modes of wrought alloys and DED builds, a variation is expected in $\delta$-precipitation in DED builds. The DED builds are shown to have strengths comparable with that of the wrought counterparts but have lower ductility properties [16-18]. These studies evaluate standard heat treatment procedures recommended for wrought and forged materials which may not be ideal for DED builds. Therefore, the DPT within the temperature range of 850 and $950^{\circ} \mathrm{C}$ for short- and long-term exposures of up to $48 \mathrm{~h}$ is considered in this work. The study reveals the differences in precipitation patterns of $\delta$-phase based on DED processing conditions and prior solution treatments through comprehensive microstructural analysis.

\section{Experimental methods}

\subsection{Equipment and material}

The DED equipment consisted of the deposition head affixed to an ISEL M40 gantry system with a coaxial nozzle (COAX50, Fraunhofer, Germany) arrangement for laser and powder delivery. Diode lasers coupled with ytterbium-doped fiber laser (IPG Photonics, Germany) were used to produce a coherent beam which was collimated and focused (focal lengths of 160 and $200 \mathrm{~mm}$, respectively) onto the substrate. A screw-type dual powder feeder arrangement (Uniquecoat Technologies, USA) was used to feed a plasma atomized alloy 718 powder with an average particle size (D50) of $79 \mu \mathrm{m}$ and chemical composition as shown in Table 1. Argon served as both carrier gas (5 1/min) and shielding gas (12 l/min) throughout the building process. Duplex steel was used as a substrate, and the dilution region at the bottom (approx. $2 \mathrm{~mm}$ ) was discarded from analysis due to the
Table 1 Chemical composition (\%wt.) of plasma atomized alloy 718 powder

\begin{tabular}{lllllllll}
\hline Elements & $\mathrm{Ni}$ & $\mathrm{Cr}$ & $\mathrm{Fe}$ & $\mathrm{Nb}+\mathrm{Ta}$ & $\mathrm{Mo}$ & $\mathrm{C}$ & $\mathrm{Ti}$ & $\mathrm{Al}$ \\
\hline Powder & 52.89 & 18.7 & 18.52 & 4.9 & 2.94 & 0.05 & 0.92 & 0.61 \\
Elements & $\mathrm{Co}$ & $\mathrm{Ta}$ & $\mathrm{B}$ & $\mathrm{Cu}$ & $\mathrm{Mn}$ & $\mathrm{Si}$ & $\mathrm{P}$ & $\mathrm{S}$ \\
Powder & 0.11 & $<0.01$ & $<0.001$ & $<0.1$ & 0.05 & 0.19 & 0.005 & 0.004 \\
\hline
\end{tabular}


chemical dilution and compositional variations at the interface of two alloys.

\subsection{Process parameters}

Two different process parameter sets, one with a high heat input and high specific energy and another with low heat input and low specific energy, were utilized in building specimens with an intent to obtain varied microstructures. The basic process parameters along with the energy conditions and capture efficiencies are as shown in Table 2. The laser power (P) was kept constant, whereas the change in speed (v) and feed rates (m) essentially resulted in varied energy conditions. The extent of overlap, which is the percentage of track width enveloped by consecutive tracks as defined by Oliari et al. [19], was varied between the two conditions. As the speed doubled from condition A (A) to condition B (B), the resultant theoretical heat input $(\mathrm{P} / \mathrm{v})$ halved from $96 \mathrm{~J} /$ $\mathrm{mm}$ in $\mathbf{A}$ to $48 \mathrm{~J} / \mathrm{mm}$ in $\mathbf{B}$. Furthermore, the feed rate in $\mathbf{B}$ was higher, and, hence, the specific energy $(\mathrm{P} / \mathrm{m})$ in $\mathbf{B}$ was lower compared to $\mathbf{A}$. These two conditions were chosen from an array of other parameters used for preliminary evaluation as they showed an aspect ratio (ratio of bead width to bead height) of 2-2.5 and capture efficiencies ( $>65 \%$ ). DED builds measuring $15 \times 20 \times 700 \mathrm{~mm}^{3}$ were built which were, in turn, used to extract specimens measuring $15 \times 20 \times 5$ $\mathrm{mm}^{3}$ for studying effects of various heat treatment protocols. The dwell time between each pass was maintained at $5 \mathrm{~s}$ to keep the inter-pass temperature below $100{ }^{\circ} \mathrm{C}$, which did not exceed even for the topmost layer. The substrates were allowed to cooldown to room temperature between successive layers. The specimens from various sections of the build were analyzed using optical microscope and scanning electron microscopes to check for microstructural differences. The results showed no major changes in terms of grain size and $\mathrm{V}_{\mathrm{f}}$ of $\mathrm{Nb}$-rich phases (Laves + carbides).

\subsection{Heat treatment}

The as-built specimens (AB) from DED process in $\mathbf{A}$ and B were subjected to heat treatments in a box-type furnace which was calibrated for various temperatures and times used in the protocols. Two different solutionizing treatments of $1010{ }^{\circ} \mathrm{C}(\mathrm{ST} 1010)$ and $1050{ }^{\circ} \mathrm{C}(\mathrm{ST} 1050)$ for $1 \mathrm{~h}$ followed by air cooling were performed. Furthermore, the AB, ST1010, and ST1050 specimens were subjected to DPT at three different temperatures: $850^{\circ} \mathrm{C}, 900{ }^{\circ} \mathrm{C}$, and $950{ }^{\circ} \mathrm{C}$ for varied dwell times of $1 \mathrm{~h}, 8 \mathrm{~h}, 24 \mathrm{~h}$, and $48 \mathrm{~h}$ followed by air cooling. Each of the 6 starting conditions was subjected to 12 different DPT protocols which resulted in 72 different conditions.

\subsection{Metallography and image analysis}

The AB- and heat-treated specimens were mounted using a Bakelite compound, ground and polished with successive steps of finer grit papers and suspensions. The specimens were etched electrolytically using a $10 \%$ oxalic acid solution at $2 \mathrm{~V}, 2 \mathrm{~A} / \mathrm{cm}^{2}$ for $15-18 \mathrm{~s}$. Furthermore, the specimens were characterized using a light optical microscope (LOM) and a scanning electron microscope (SEM). The SEM images were characterized at a working distance (WD) of $7.5-8 \mathrm{~mm}$ with an accelerating voltage of $5-10 \mathrm{kV}$. Electron backscatter diffraction (EBSD) analysis was performed at a higher voltage of $20 \mathrm{kV}$ at a WD of $12-14.5 \mathrm{~mm}$ on specimens that were mechanically polished using a vibratory polisher. AZtecCrystal 2.0 was used for processing EBSD data and to analyze grain data. The grain sizes are expressed in terms of ASTM grain number $(\mathrm{G})$ in accordance with ASTM E112 standard [20].

The LOM and SEM images were analyzed using ImageJ software V1.53c. A minimum of 50 dendrite colonies were analyzed to measure the arm spacing. For analyses of $V_{f}$ of $\mathrm{Nb}$-rich and $\delta$-phases, a minimum of 8 fields under 2 different magnifications $(3000 \times$ and $5000 \times)$ were considered. The average $\delta$-precipitate length was taken from measuring at least $50 \delta$-plates from 6 different fields so that the variation is accurately depicted.

\section{Results and discussions}

\subsection{As-built microstructure}

The microstructure of $\mathrm{AB}$ deposits at high and low energy conditions (see Table 2) is as shown in Fig. 1a and b. The specimens in $\mathrm{AB}$ condition predominantly show columnar-dendritic microstructure, typical of DED builds. The

Table 2 Process parameters and resultant properties used for building specimens

\begin{tabular}{lllllllll}
\hline Condition & Power $(\mathrm{W})$ & Speed $(\mathrm{mm} / \mathrm{s})$ & $\begin{array}{l}\text { Feed rate } \\
(\mathrm{g} / \mathrm{min})\end{array}$ & $\begin{array}{l}\text { Extent of } \\
\text { overlap }(\%)\end{array}$ & $\begin{array}{l}\text { Theoretical Heat } \\
\text { input }(\mathrm{J} / \mathrm{mm})\end{array}$ & $\begin{array}{l}\text { Specific } \\
\text { energy } \\
(\mathrm{kJ} / \mathrm{g})\end{array}$ & $\begin{array}{l}\text { Capture effi- } \\
\text { ciency }(\%)\end{array}$ & $\begin{array}{l}\text { Grain size } \\
(\mathrm{ASTM} \text { G) }\end{array}$ \\
\hline $\mathrm{A}$ & $800 \pm 8$ & 8.33 & 6.7 & 60 & $96 \pm 1$ & 7.2 & 77 & 4.7 \\
$\mathrm{~B}$ & $800 \pm 8$ & 16.67 & 10.3 & 45 & $48 \pm 0.5$ & 4.7 & 66 & 6 \\
\hline
\end{tabular}



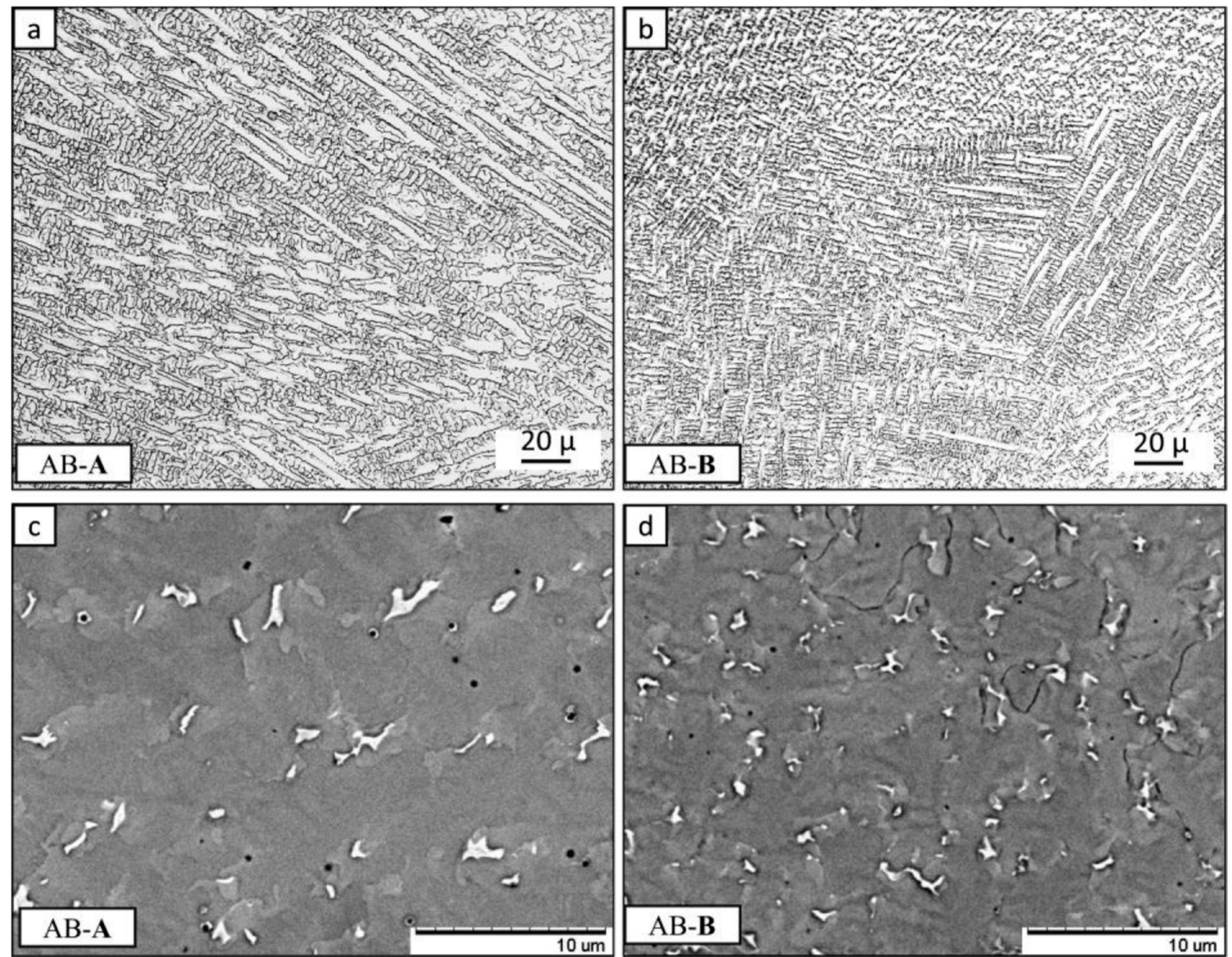

Fig. 1 Micrographs showing dendritic substructures and Nb-rich precipitates in a, $\mathbf{c} A B-A$ and $\mathbf{b}, \mathbf{d}$ AB-B specimens

different processing conditions result in varied microstructural features such as secondary dendritic arm spacing $\left(\lambda_{2}\right)$ and grain size. The measured values of $\lambda_{2}$ in $\mathrm{AB}-\mathbf{A}$ and AB-B specimens are $2.55 \pm 0.35$ and $1.82 \pm 0.08 \mu \mathrm{m}$, respectively. The cooling rate $(\mathrm{T})$ is related to secondary dendritic arm spacing through a relationship, $\lambda_{2}=\mathbf{a} \mathrm{T}^{-\mathrm{n}}$, where $\mathbf{a}$ and $\mathrm{n}$ are material-specific constants $[21,22]$. Based on the works of Patel et al. [23] and Nie et al. [24], the values of $\mathbf{a}$ and $\mathrm{n}$ for alloy 718 are 32 and 0.31 , respectively. Cooling rates of $3500{ }^{\circ} \mathrm{C} / \mathrm{s}$ and to $10,500{ }^{\circ} \mathrm{C} / \mathrm{s}$ are obtained for $\mathrm{AB}-\mathrm{A}$ and $\mathrm{AB}-\mathrm{B}$, which shows that high-energy input results in relatively low cooling rate. Consequently, AB-A specimens had relatively larger grain size corresponding to ASTM G4.7 compared to ASTM G6 in case of AB-B, as evident from EBSD analysis further elaborated in Sect. 3.3.

The SEM analysis of AB-A and AB-B specimens as seen in Fig. 1c and d shows the presence of Nb-rich phases (bright particles - Laves and $\mathrm{NbC}$ ) in the interdendritic region and $\mathrm{MC}$ type carbides (dark particles - $\mathrm{TiC} / \mathrm{TiN}$ ) in dendrites and dendritic cores regions, as confirmed by earlier research of DED built specimens [25, 26]. The amount of $\mathrm{Nb}$-rich phases is of primary importance as this can affect the precipitation of $\gamma^{\prime \prime}$ and $\delta$ phases upon aging treatments [27]. The $\mathrm{V}_{\mathrm{f}}$ of $\mathrm{Nb}$-rich phases in $\mathrm{AB}-\mathrm{A}$ is $2.87 \%$ compared to $1.9 \%$ in $\mathrm{AB}-\mathrm{B}$, indicating the influence of cooling rates on segregation behavior of L-DED processed alloy 718. A similar conclusion on increase in Laves phase with increase in processing energy conditions was reached by other researchers $[28,29]$. The cooling rate also influences the average size of $\mathrm{Nb}$-rich precipitates in $\mathrm{AB}-\mathrm{A}$ and $\mathrm{AB}-\mathbf{B}$ which are $0.38 \mu \mathrm{m}^{2}$ and $0.18 \mu \mathrm{m}^{2}$, respectively. A SEM micrograph with $5000 \times$ magnification consisted of 54 and 79 particles in AB-A and AB-B with an average length between nearestneighbor particles measuring $7.2 \mu \mathrm{m}$ and $4.5 \mu \mathrm{m}$, respectively, which is a further confirmation of varied distribution of precipitates as a consequence of processing conditions. 

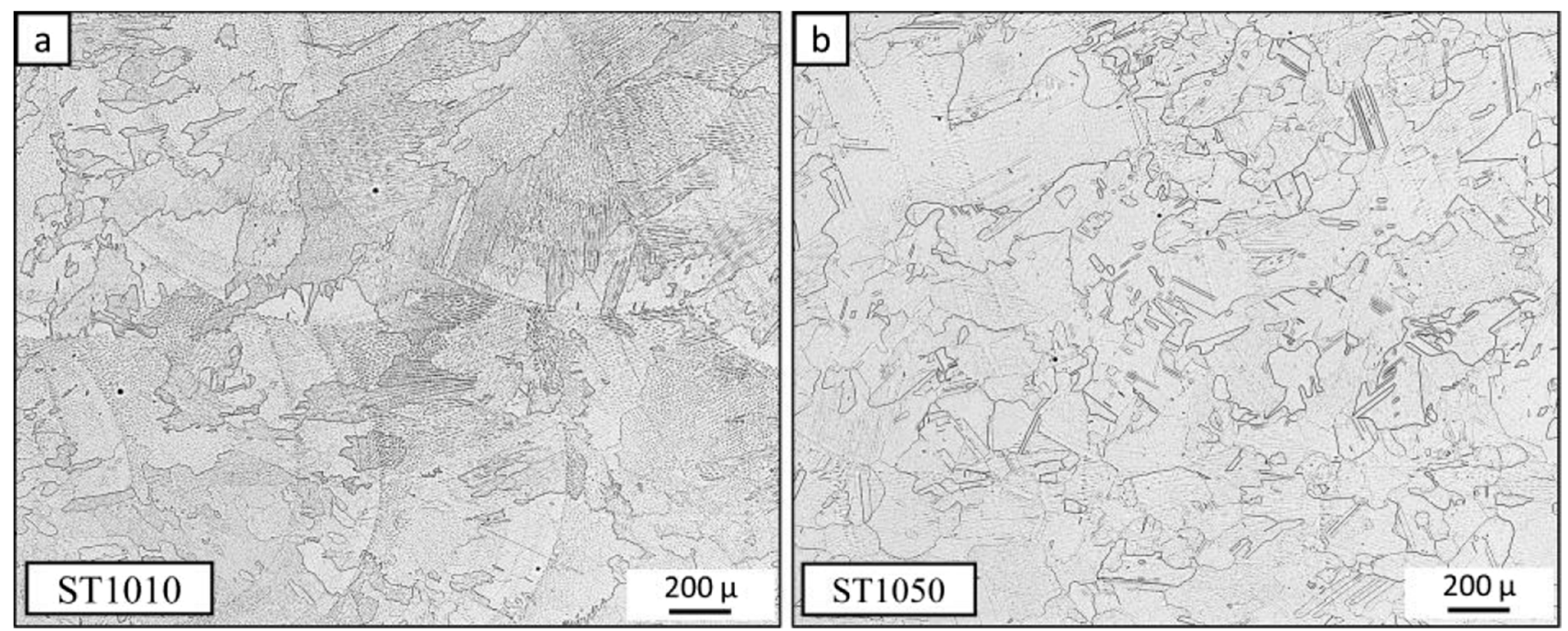

Fig. 2 AB-A specimens subjected to solutionizing treatment of at $\mathbf{a} 1010{ }^{\circ} \mathrm{C} / 1 \mathrm{~h}$ and $\mathbf{b} 1050{ }^{\circ} \mathrm{C} / 1 \mathrm{~h}$

In a research performed by Chen et al. [30], laser beam having varied energy distribution was used to produce DED specimens with higher $\mathrm{V}_{\mathrm{f}}$ of long-striped, fine $\mathrm{Nb}$-rich precipitates and lower $\mathrm{V}_{\mathrm{f}}$ of discrete, coarse $\mathrm{Nb}$-rich precipitates. The specimen with discrete, coarse precipitates showed higher tensile strength compared to the one with fine particles, although both specimens showed similar ductility. Chen et al. attributed the higher $V_{f}$ of long-striped, fine precipitation of Laves phase as the reason for loss of strength in the material. The study also shows the importance of morphology, distribution, and amount of precipitation on properties of alloy 718 .

\subsection{Effect of solution treatment}

Specimens from $\mathrm{AB}$ condition were subjected to solution heat treatments in order to minimize inhomogeneities caused by the segregation of Nb-rich phases. A total of $1010{ }^{\circ} \mathrm{C}$ and $1050{ }^{\circ} \mathrm{C}$ are chosen as solutionizing temperatures as they correspond to delta solvus and stress-relieving temperatures for alloy 718 [31]. A better homogenization is achieved in ST1050 condition compared to ST1010 as the mobility of $\mathrm{Nb}$ atoms increases with temperature, accompanied by GB migration which results in increased grain size.
As seen in Fig. 2a and b, the solidification substructures such as dendrites are legible in specimens that undergo ST1010, whereas specimens that undergo ST1050 show annealing twins indicative of recrystallization. The grain sizes in AB-A and AB-B are ASTM 4.7 and 6, respectively. In $A B-A$, there is no indication of grain growth when subjected to ST1010, whereas considerable grain growth is noticed when subjected to ST1050. A relatively fine-grained AB-B shows grain growth under both ST1010 and ST1050 conditions. The larger grains grow at the expense of smaller grains during grain growth due to GB diffusion [32]. Therefore, the fine-grained AB-B specimens show higher amount of grain growth compared to AB-A condition.

\subsection{EBSD analysis}

The EBSD analysis that shows variations in grain morphology and texture, depending on the DED process and solution treatment conditions, is tabulated in Table 3 . The AB specimens show a steady increase in grain size when subjected to ST1010 and ST1050 treatments except for AB-A specimen subjected to ST1010 as seen in the IPF textural maps in Fig. 3. The small-angle grain boundaries (SAGBs) made of dislocations networks get annihilated upon heat treatment, and, therefore, the \%SAGBs gradually reduce from about
Table 3 Data from EBSD analysis for various specimen conditions

\begin{tabular}{lllllll}
\hline Condition & AB-A & AB-B & A+ST1010 & B+ST1010 & A+ST1050 & B+ST1050 \\
\hline ASTM G & 4.7 & 6 & 4.7 & 4.2 & 3.7 & 3.9 \\
\%SAGB $\left(2-15^{\circ}\right)$ & 39 & 29 & 20 & 17 & 2 & 14 \\
\%grains twinned & 0.56 & 0.97 & 1.98 & 2.66 & 68 & 39 \\
Average aspect ratio & 2.7 & 3.2 & 2.6 & 3.1 & 1.9 & 2.7 \\
\hline
\end{tabular}



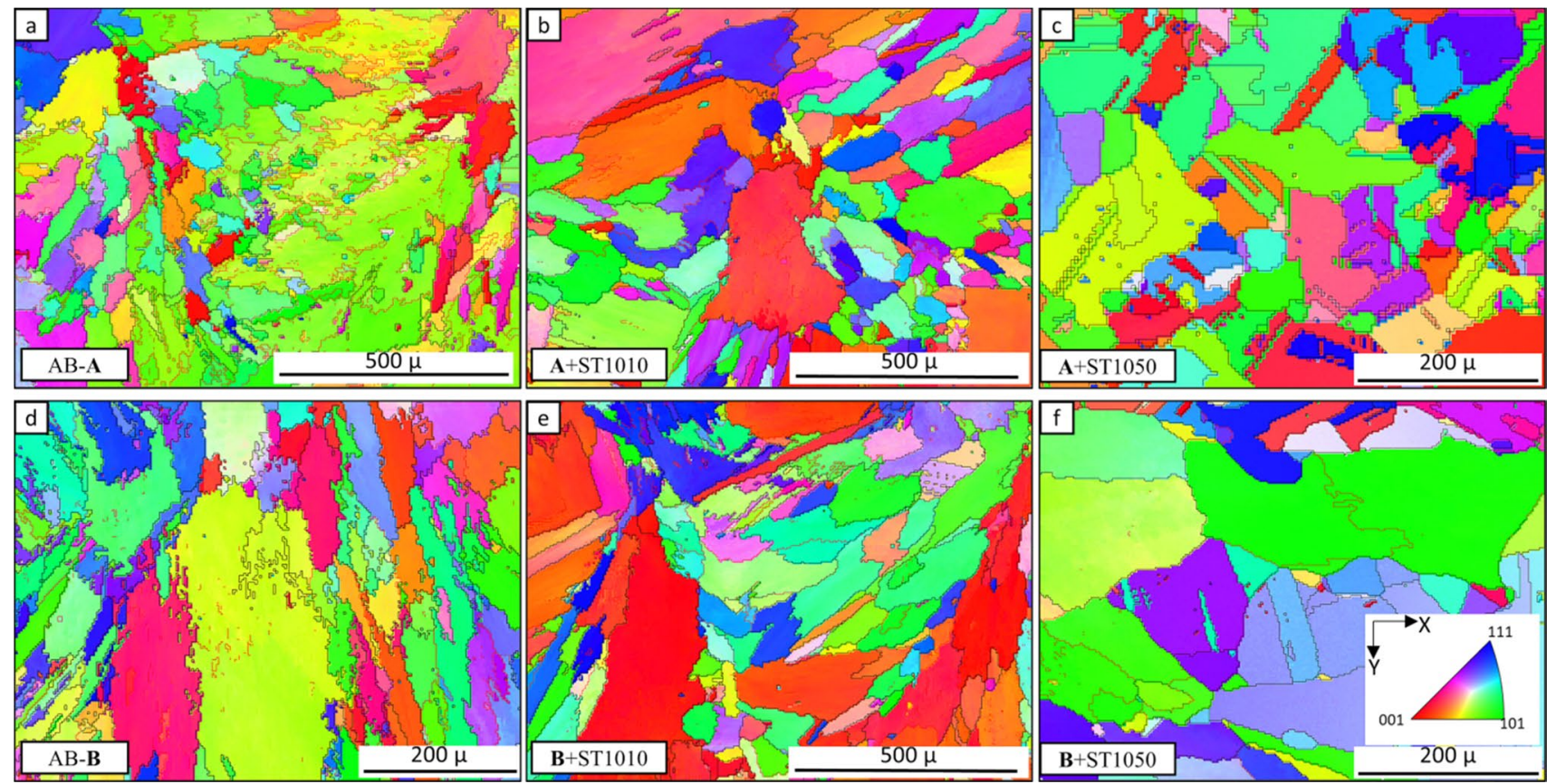

Fig. 3 EBSD inverse pole figures textural maps showing grain orientation parallel to the build direction for a AB-A; b A+ST1010; $\mathbf{c}$ A + ST1050; d AB-B; e B + ST1010; f B + ST1050

$39 \%$ in AB-A condition to $20 \%$ and $2 \%$ when subjected to ST1010 and ST1050 treatments, respectively. A similar trend is found in AB-B in which the initial \%SAGB of $29 \%$ is reduced to $17 \%$ and $14 \%$ upon ST1010 and ST 1050 treatments. The strain in the specimens due to processing condition, especially the energy input and extent of overlap, plays an important role in governing the initial amount of SAGBs in the DED builds and, in turn, the formation of annealing twins upon heat treatments as indicated by Cao et al. [33]. ST1050 treatment generally used for stress relieving shows a higher rate of recrystallization indicated by percentage of grains twinned, which is $68 \%$ in case of $\mathrm{AB}-\mathrm{A}$ compared to $39 \%$ in AB-B. As AB-A displays higher degree of recrystallization, more SAGBs participate in the formation of twin boundaries compared to AB-B specimens which have a $14 \%$ SAGBs at the termination of ST1050 treatment. A study performed by Li et al. [34] showed that increase in deformation from 30 to $70 \%$ resulted in increased twin boundaries in alloy 718 , indicating the effect of strain on recrystallization. Also, the fraction recrystallization increased from 24 to $50 \%$ on increasing the solution treatment temperature from 1000 to $1040{ }^{\circ} \mathrm{C}$, with greater extent of twinning noted at higher temperature corroborating results observed in this research. The (001) pole figures for specimens in AB condition show a strong textural orientation in $<101>$ direction. Specimens subjected to ST1010 condition show a relatively weaker texture compared to $\mathrm{AB}$ conditions, having a preferred orientation of $<001>$ along the build axis.
A random orientation is found in specimens subjected to ST1050 with (100) pole figure indicating a very weak texture in $<111>$ and $<101>$ directions. Twinning is found to introduce a more random texture with less elongated grains in the specimens indicated by the average aspect ratio changes from 2.7 to 1.9 in case $\mathbf{A}$ and from 3.2 to 2.7 in case $\mathbf{B}$ when subjected to ST1050. A study by Smith et al. [35] showed the microstructure of as-produced direct metal laser sintered (DMLS) specimen showed a strong texture in $<100>$ direction built horizontally, vertically, and diagonally to the built plate. However, upon post-processing through hot isostatic pressing treatment, all the specimens showed random texture with recrystallized microstructure. Formation of annealing twins is noted in specimens subjected to solution treatment, and prior reports have shown these to be beneficial in enhancing material properties both in terms of strength and ductility of material [36].

\subsection{Effect of delta processing treatment}

\subsubsection{Effect of delta processing treatments on as-built specimens}

AB specimens subjected to direct DPT show precipitation of intragranular $\delta$-phase predominantly in interdendritic region accompanied by fair amounts of Laves phase as shown in Fig. $4 \mathrm{a}-\mathrm{d}$. In DED builds, $\mathrm{Nb}$ preferably partitions into interdendritic region during solidification leading to $\mathrm{Nb}$-rich 

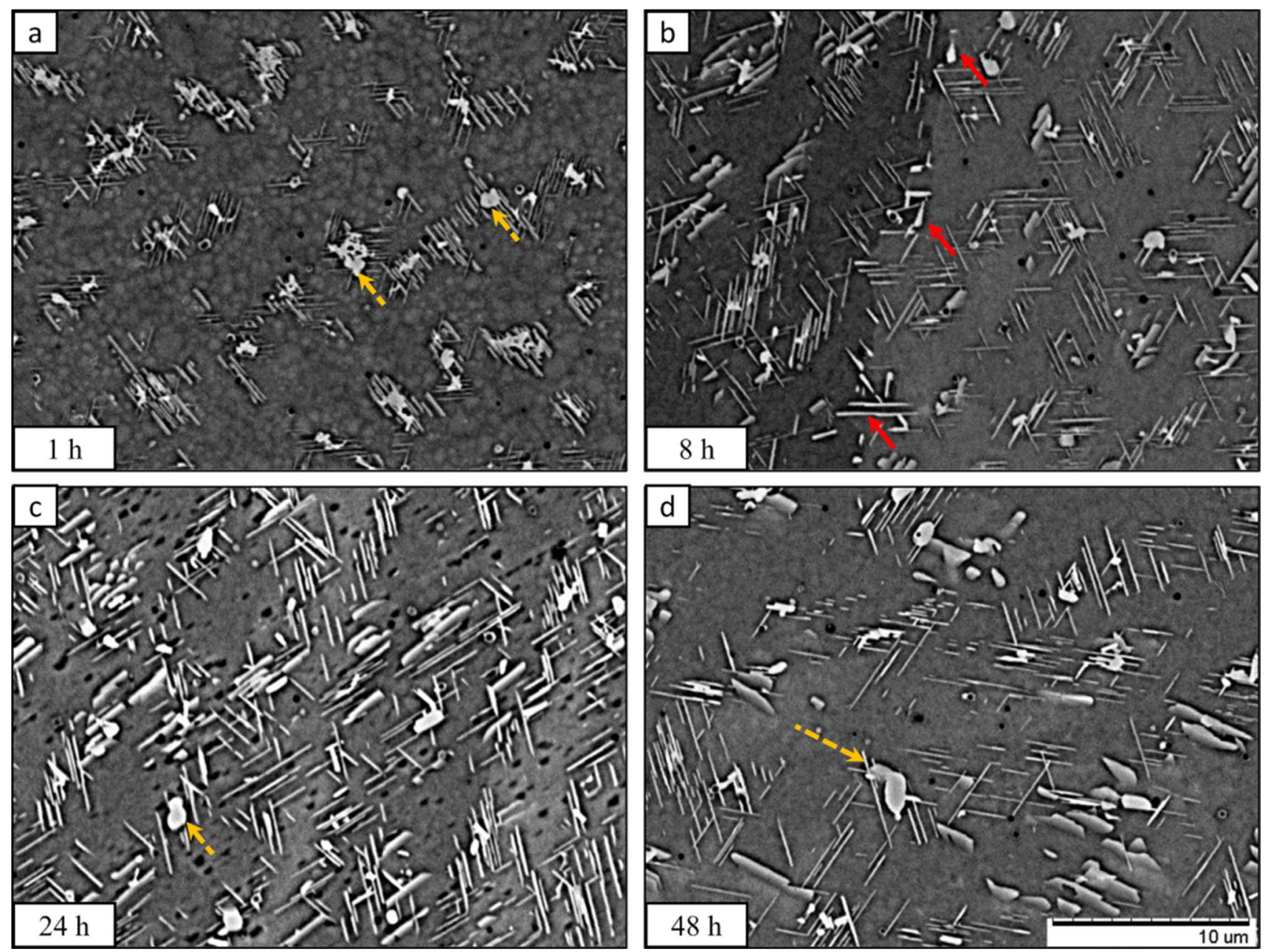

Fig. 4 Micrographs showing $\delta$-phase precipitation when AB-A specimens subjected to DPT at $900{ }^{\circ} \mathrm{C}$ for treatment times of a $1 \mathrm{~h}, \mathbf{b} 8 \mathrm{~h}, \mathbf{c} 24 \mathrm{~h}$, and $\mathbf{d} 48 \mathrm{~h}$ (the red arrows indicate the intergranular delta precipitates and yellow arrow indicates the Nb-rich Laves phase)

segregates, which is a preferable site for $\delta$-precipitation [26, 37]. Interfacial strain energy due to lattice misfit between matrix and an incoherent phase (either Laves or $\delta$-phase) leads to increase in dislocation density as mentioned by Mahadevan et al. [2] in their research, which results in precipitation of $\delta$-phase in interdendritic regions.

The material in $\mathrm{AB}$ condition showed variations in grain size, segregation, and $\mathrm{Nb}$-rich phase distribution due to different processing conditions as discussed in Sect. 3.1. Post DPT, the specimens in $\mathbf{A}$ and $\mathbf{B}$ conditions show minor differences in $\% \mathrm{~V}_{\mathrm{f}}$ and average length of $\delta$-precipitates as shown in Fig. 5. Upon DPT, the Laves phase tend to solutionize as the temperatures are high enough for diffusion of $\mathrm{Nb}$. Longer exposure times lead to better dissolution of $\mathrm{Nb}$-rich phases, irrespective of $\mathrm{AB}$ specimen condition which effects similar precipitation morphology and phase fraction upon DPT protocols. Although the Laves phase were excluded during ImageJ analysis based on the appearance, thickness, and sphericity factors, an error of $\pm 0.6 \%$ is expected in estimating $V_{f}$ of $\delta$-phase for $A B$ conditions based on the metallographic preparations and filters applied when performing image analysis.

For AB specimens subjected to shorter time DPT of $1 \mathrm{~h}$ (Fig. 4a), the $\mathrm{V}_{\mathrm{f}}(0.5-3 \%)$ and the average length of $\delta$-precipitates are quite small $(0.5-1.5 \mu \mathrm{m})$ as seen in Fig. 5a-d (indicated by circle motifs) compared to solutiontreated conditions. When the time of treatment increases from 1 to $8 \mathrm{~h}$, intergranular $\delta$-precipitates are formed at the GBs (indicated by red arrows in Fig. 4b). This might be the result of dissolution of Nb-rich phase such as Laves (marked by yellow arrows in Fig. 4a, b, and d) during longtime exposures. Similar results of Laves dissolution have been reported for laser-DED [26] and laser welding [38] processes. Morphologically, the intergranular $\delta$-phase appears as thicker and shorter globular, blocky, or plate-like precipitates (indicated by red arrows in Fig. 4b) compared to acicular intragranular $\delta$-phase [2]. A grouping of data points is observed in $950{ }^{\circ} \mathrm{C}$ DPT for $\mathrm{V}_{\mathrm{f}}$ of around $4 \%$, which shows 


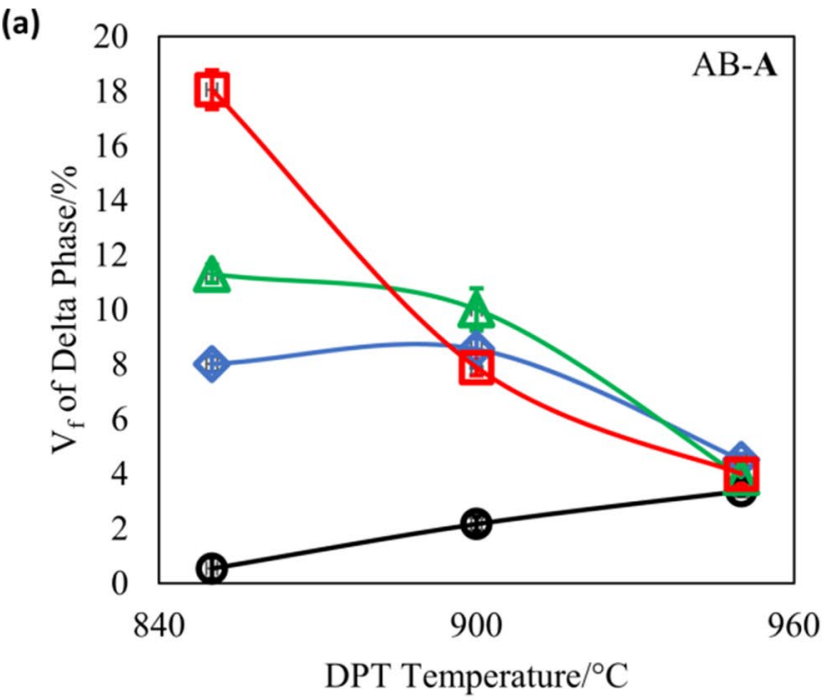

- $\mathrm{A}-1 \mathrm{hr} \longrightarrow \mathrm{A}-8 \mathrm{hr} \leftarrow \mathrm{A}-24 \mathrm{hr} \rightarrow \mathrm{A}-48 \mathrm{hr}$

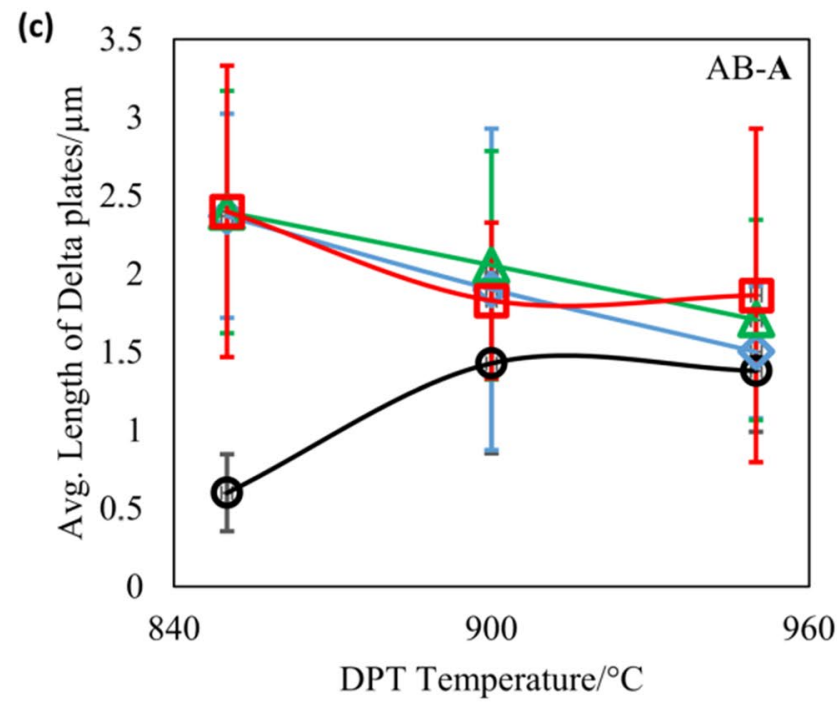

- $\mathrm{A}-1 \mathrm{~h}-\mathrm{A}-8 \mathrm{~h} \rightarrow \mathrm{A}-24 \mathrm{~h}-\mathrm{E}-\mathrm{A}-48 \mathrm{~h}$ (b)

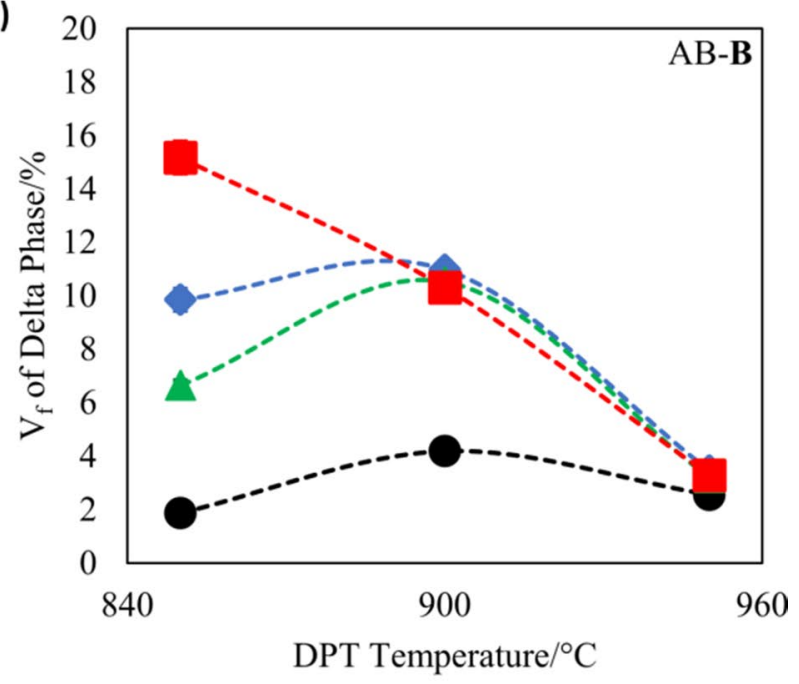

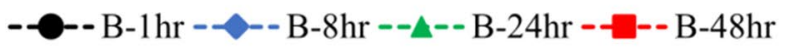

(d)

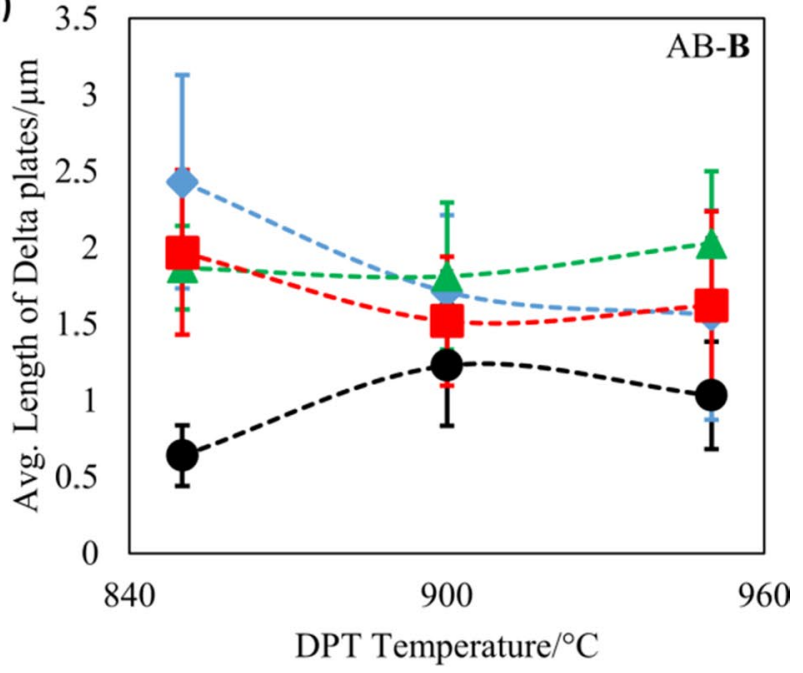

$-B-1 \mathrm{~h}-\rightarrow--B-8 \mathrm{~h}--4--B-24 \mathrm{~h}--\mathrm{D}--\mathrm{B}-48 \mathrm{~h}$

Fig. 5 Analysis of $\delta$-phase volume fraction in specimens a AB-A, b AB-B; and $\delta$-precipitate length in $\mathbf{c}$ AB-A, $\mathbf{d}$ AB-B subjected to DPT

saturation of $\delta$-phase precipitation, thereby rendering longtime treatments ineffective. However, subtle changes in morphology are noticed. A similar observation of grouping can be made for $900{ }^{\circ} \mathrm{C} \mathrm{DPT}$ for longer exposure times of 8,24 , and $48 \mathrm{~h}$ for a $\mathrm{V}_{\mathrm{f}}$ of about $10 \%$, which is indicative of an equilibrium volume fraction of $\delta$-phase being reached under these DPT conditions. The study of $\delta$-phase precipitation in different forms of forged alloys Azadian et al. [39] showed similar treatment times (long-term exposure) to reach equilibrium phase fraction. The average length of the $\delta$-precipitates $(2.5-3.5 \mu \mathrm{m})$ in AB + DPT condition does not vary much for treatment times of 8,24 , and $48 \mathrm{~h}$, although an increase in $\mathrm{V}_{\mathrm{f}}$ of $\delta$-phase indicates an increase in density of precipitates and appearance of plate-like intragranular- $\delta$ at higher temperatures and treatment times. The scatter in data for length of $\delta$-precipitates vs. DPT for long exposure times as shown in Fig. 5c and $d$ is due to the nucleation and growth of $\delta$-precipitates at different junctures of time during treatment. This observation is similar to delta precipitation sequence in wrought materials as reported by Azadian et al. [39] and Anderson et al. [8]. Moreover, only subtle changes exist in $V_{f}$ of $\delta$-precipitates in AB-A and AB-B specimens subjected to DPT, and the length scales almost appear the same for both conditions. 
Kuo et al. [40] showed that the tensile strength and ductility properties of DMLS alloy 718 specimens were a function of build direction when subjected to delta precipitation treatment and aging (DPT + A) as well as direct aging (DA) conditions. The horizontally built DT $+\mathrm{A}$ specimens showed least ductility as the $\delta$-phase precipitates had a preferred orientation perpendicular to the loading direction. The loss of ductility can be attributed to the presence of Laves phase along with $\delta$-precipitates as discussed by [41]. The Laves phase precipitates lead to the formation of micro-voids under loading, and the $\mathrm{Nb}$-denuded zones in the vicinity of $\delta$-phase can lead to debonding resulting in the loss of ductility. The effect of varied volume fraction of interdendritic $\delta$-precipitates on mechanical properties of alloy 718 needs further investigation, although higher amounts of $\delta$-precipitation are found to have negative effects on ductility properties [13].
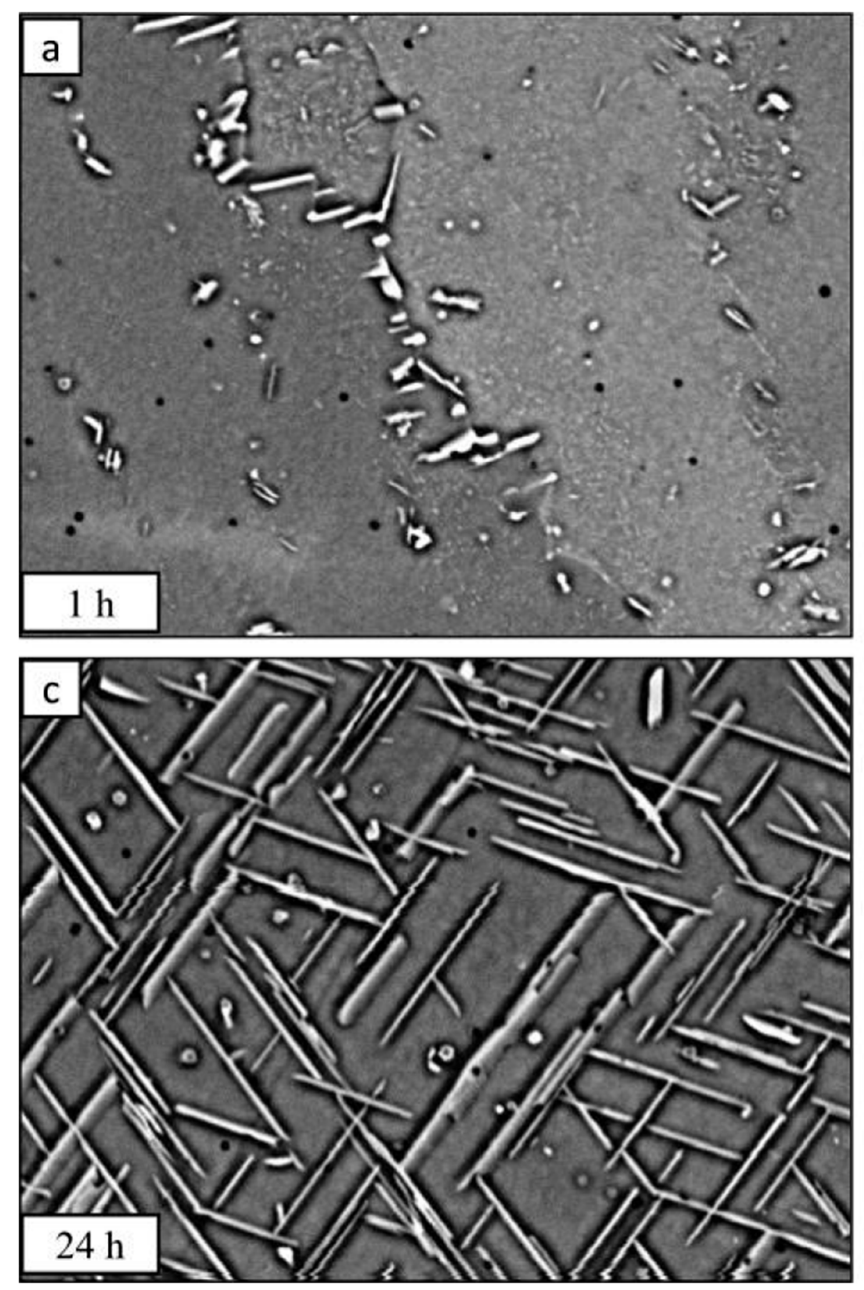

\subsubsection{Effect of DPT on as-built specimens subjected to solution treatment at $1010^{\circ} \mathrm{C} / 1 \mathrm{~h}$}

When the $\mathrm{AB}$ specimens are subjected to an intermediate solution treatment before DPT, noticeable change occurs in the precipitation pattern as shown for AB-A specimens in Fig. 6a-d. The precipitation changes from predominantly interdendritic- $\delta$ in $\mathrm{AB}+\mathrm{DPT}$ to intergranular $\delta$-phase (Fig. 6a) for short-term aging of $1 \mathrm{~h}$ in AB + ST1010+DPT treatment. As the dendritic boundaries are solutionized, a $\mathrm{Nb}$-saturated gamma matrix is formed. This results in longer $\delta$-precipitates compared to $\mathrm{AB}+\mathrm{DPT}$ for exposure times of $8 \mathrm{~h}$ and more as seen in Fig. 7a-d. However, for longer times of exposure, intragranular $\delta$-precipitates outnumber the amount of intergranular $\delta$-phase, similar to the research findings of Anderson et al. [8]. Noticeably, the length of the $\delta$-precipitates increases with time between 1 and $24 \mathrm{~h}$, and no appreciable changes can be seen between 24 and $48 \mathrm{~h}$ for both $\mathbf{A}$ and $\mathbf{B}$ specimens. Similar to AB + DPT, for
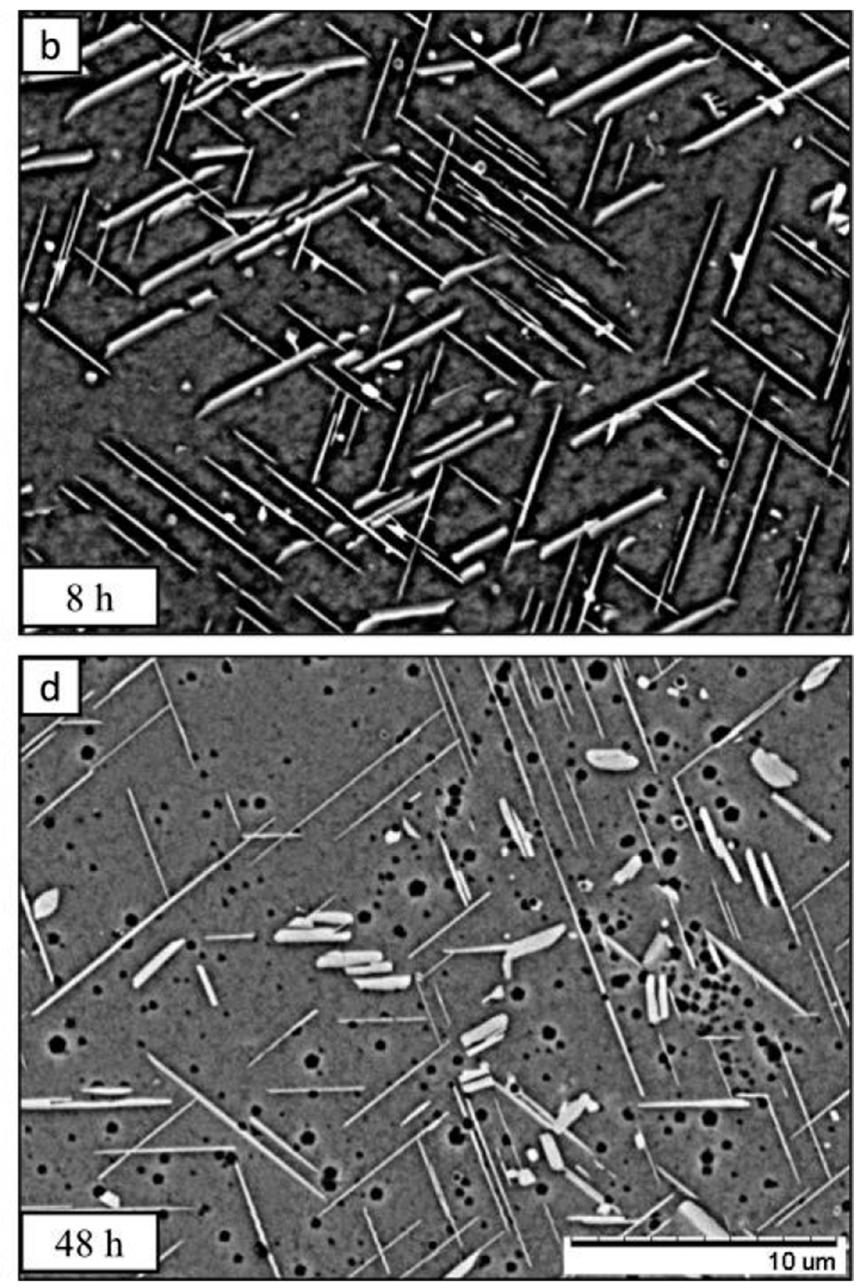

Fig. 6 Micrographs showing $\delta$-phase precipitation when AB-A specimens subjected to ST1010 and DPT at $900{ }^{\circ} \mathrm{C}$ for treatment times of a $1 \mathrm{~h}$, b $8 \mathrm{~h}, \mathbf{c} 24 \mathrm{~h}$, and d $48 \mathrm{~h}$ 


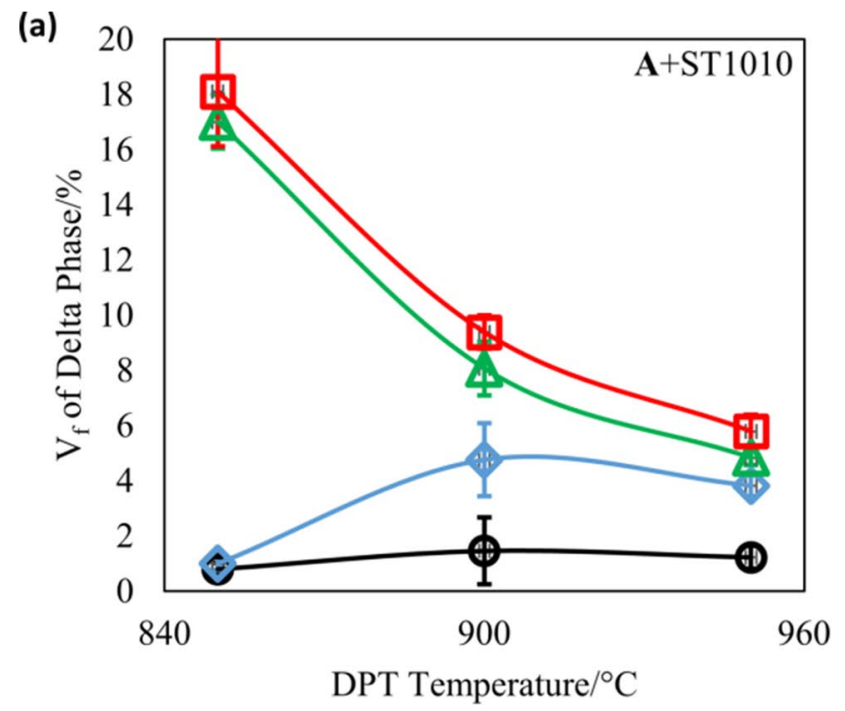

-A-1hr $-\mathrm{A}-8 \mathrm{hr}-\mathrm{A}-24 \mathrm{hr} \bullet \mathrm{A}-48 \mathrm{hr}$

(c)

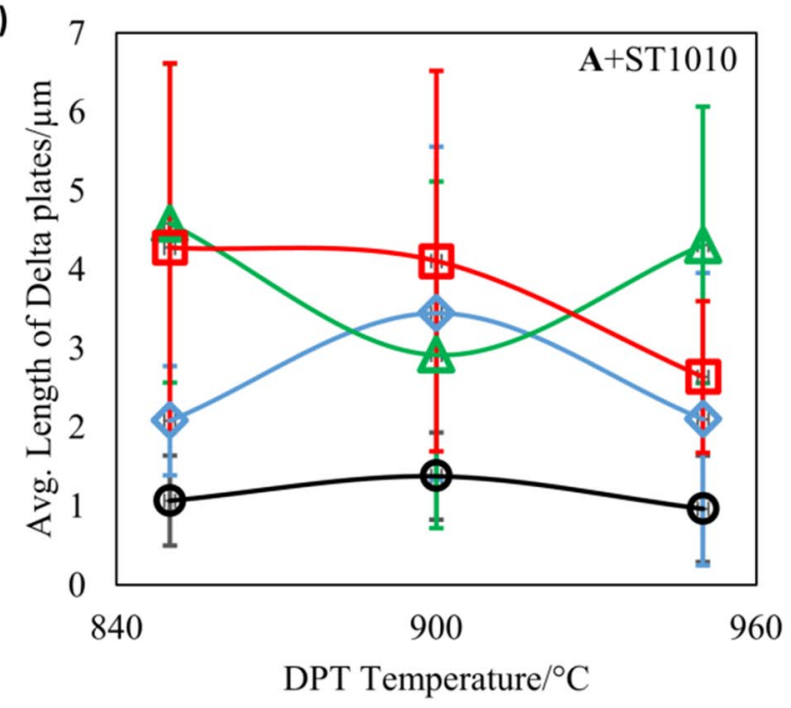

- $\mathrm{A}-1 \mathrm{~h}-\mathrm{A}-8 \mathrm{~h}-\mathrm{A}-24 \mathrm{~h}-\mathrm{A}-48 \mathrm{~h}$

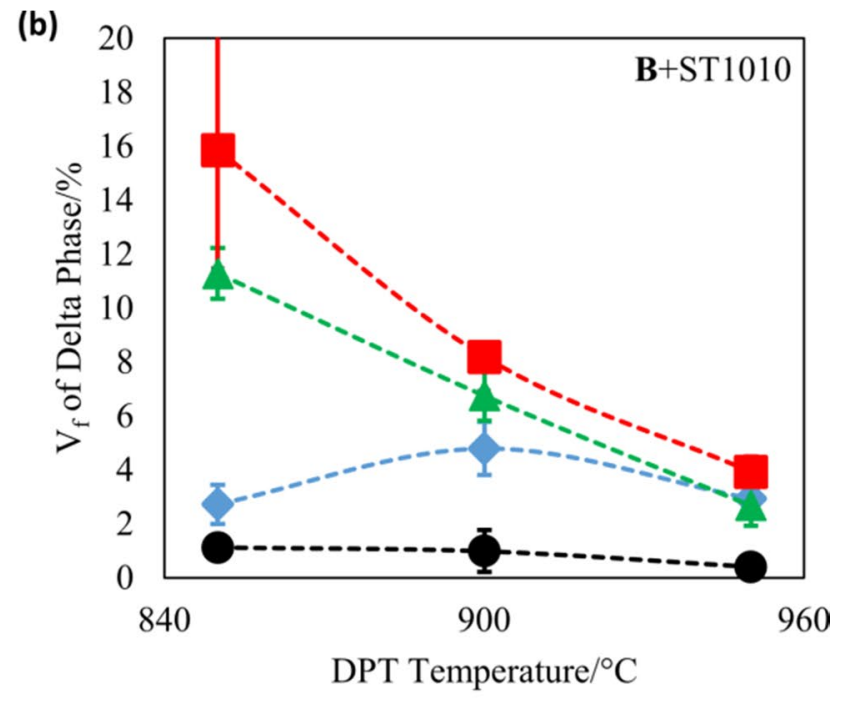

B-1hr - - - B-8hr -- - - B-24hr - - - B-48hr

(d)

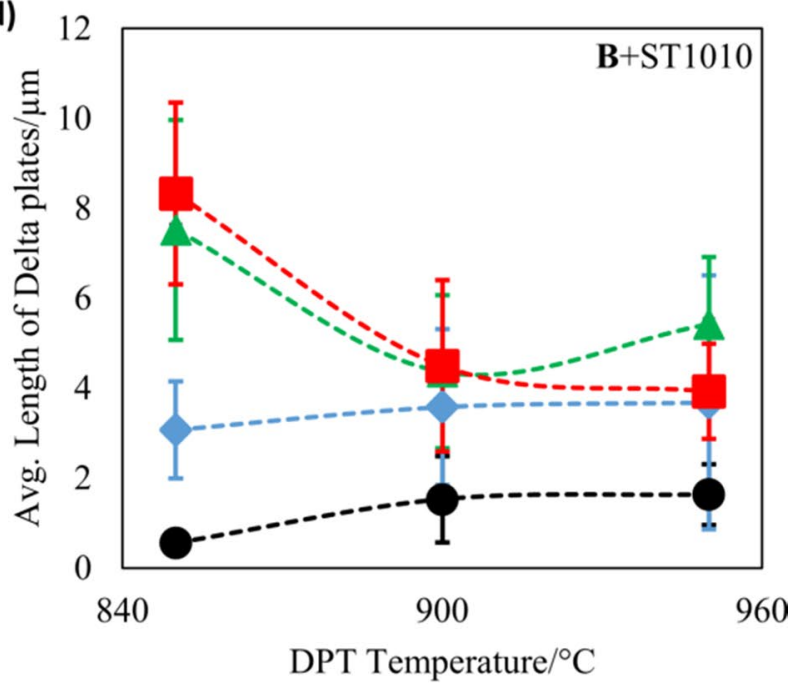

$---B-1 h-\neg--B-8 h--A--B-24 h-\neg--B-48 h$

Fig. 7 Analysis of $\delta$-phase volume fraction in specimen $\mathbf{a}$ A, b B; and $\delta$-precipitate length in specimen $\mathbf{c}$ A, $\mathbf{d}$ B; subjected to ST1010 and DPT protocols

long-term exposures $(8-24 \mathrm{~h}), \% \mathrm{~V}_{\mathrm{f}}$ of $\delta$-phase at $950{ }^{\circ} \mathrm{C}$ is approximately $5 \%$.

The tensile strength and ductility properties of specimens subjected to DPT protocols between the temperature range of 875 and $975{ }^{\circ} \mathrm{C}$ showed no correlation with the $\mathrm{V}_{\mathrm{f}}$ of $\delta$-precipitation [8], although the temperature of treatment dictated the strength and ductility property of alloy 718 , where the higher temperature of treatment corresponded with better ductility but reduced tensile and yield strengths. The specimens subjected to DPT at $875^{\circ} \mathrm{C} / 0.5 \mathrm{~h}$ having about $1 \% \mathrm{~V}_{\mathrm{f}}$ of $\delta$-phase showed better strength compared to specimens that are subjected to DPT at $900{ }^{\circ} \mathrm{C} / 24 \mathrm{~h}\left(16 \% \mathrm{~V}_{\mathrm{f}}\right.$ of $\delta$-phase), attributable to the presence of $\gamma^{\prime \prime}$-precipitates at $875{ }^{\circ} \mathrm{C}$.

\subsubsection{Effect of DPT on as-built specimens subjected to solution treatment at $1050{ }^{\circ} \mathrm{C} / 1 \mathrm{~h}$}

Upon subjecting AB specimens to ST1050 and DPT protocols, intergranular $\delta$-phase is precipitated at the GBs for short-term exposure $(1 \mathrm{~h})$ as seen in Fig. $8 \mathrm{a}$, which is similar to AB + ST1010+ DPT protocol discussed in Sect. 3.4.2 

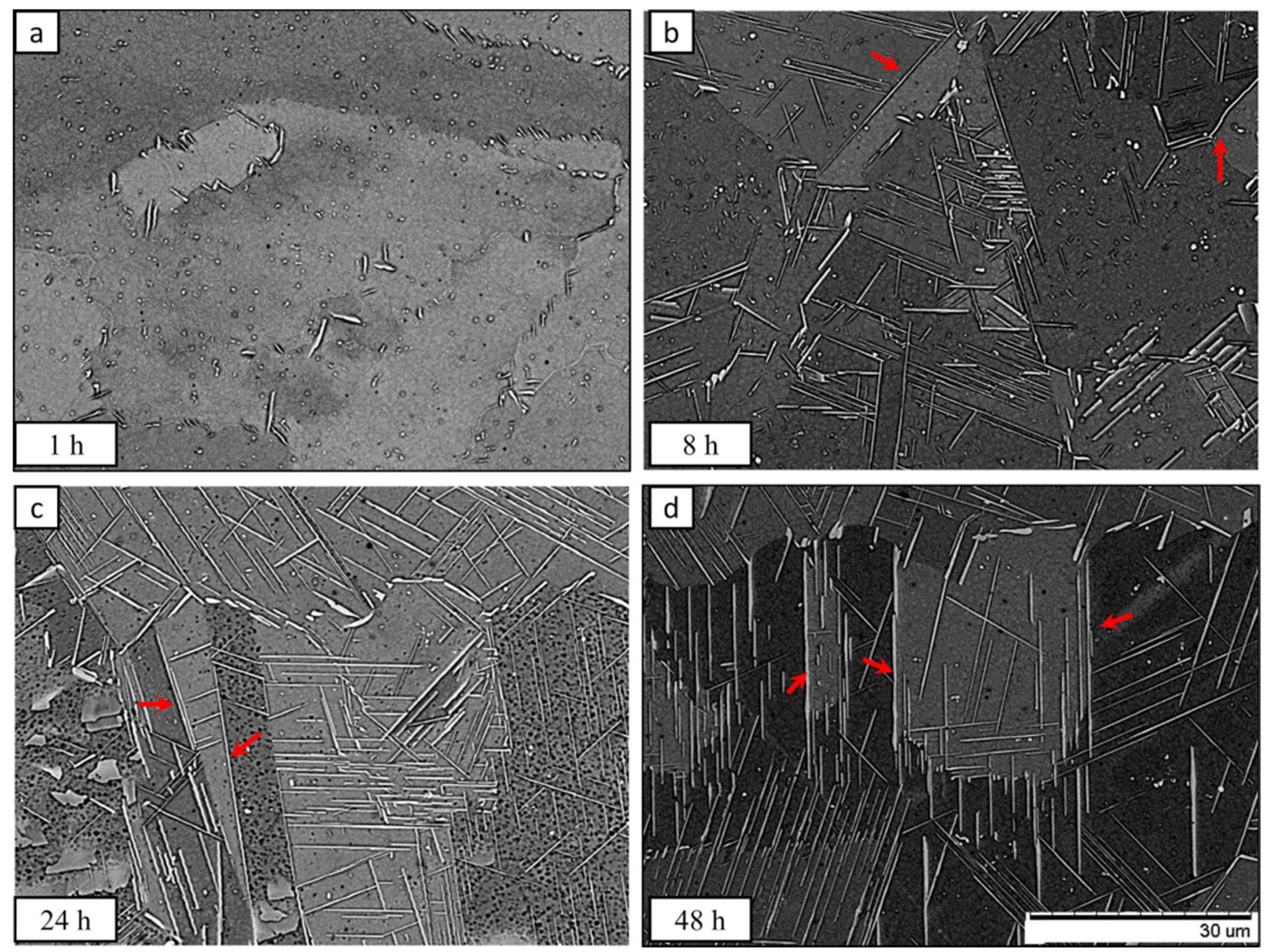

Fig. 8 Micrographs showing $\delta$-phase precipitation when AB-A specimens subjected to ST1050 and DPT at $900{ }^{\circ} \mathrm{C}$ for treatment times of a $1 \mathrm{~h}$, b $8 \mathrm{~h}, \mathbf{c} 24 \mathrm{~h}$, and $\mathbf{d} 48 \mathrm{~h}$ (the arrows indicate the location of long-striped intergranular $\delta$-plates)

(Fig. 6a). For long-term exposures (8-48 h), predominantly intragranular $\delta$-phase precipitates are noticeable (Fig. 8b-d) along with long-striped intergranular- $\delta$. The $\delta$-phase precipitates have the highest average length in $\mathrm{AB}+\mathrm{ST} 1050+\mathrm{DPT}$ condition (Fig. 9c and d) compared to $\mathrm{AB}+\mathrm{DPT}$ and $\mathrm{AB}+\mathrm{ST} 1010+\mathrm{DPT}$ protocols. ST1050 offers better homogenization compared to ST1010 condition, as reflected in the lower number of $\mathrm{Nb}$-rich precipitates which act as sites for $\delta$-phase precipitation. This minimizes the density of intragranular $\delta$-phase precipitates in ST1050 condition subjected to DPT protocols. The $\delta$-phase precipitates, although fewer, tend to grow longer which influences the total $V_{f}$ of $\delta$-phase in $\mathrm{AB}+\mathrm{ST} 1050+\mathrm{DPT}$ condition (Fig. 9a and b).

Upon solution treatment, the specimens undergo changes in terms of crystallography and microstructure. The elimination of dendritic substructures on solution treatment of $A B$ specimen changes the interdendritic precipitation morphology of $\delta$-phase upon DPT. The saturation of Nb on solution treatment [26] promotes formation of intergranular $\delta$-phase at the GBs which are defects and offers nucleation sites for $\delta$-precipitation [2]. The shearing of $\delta$-precipitates as described by Mahadevan et al. [2] was noticed in solutiontreated specimens undergoing DPT treatments as seen in Fig. 6 and Fig. 8. The precipitation pattern upon solution treatment and DPT of DED specimens resembles that of wrought alloys $[8,39]$. The number of precipitates per unit area in specimens undergoing ST1050 treatment appears to be lower compared to ST1010 specimens upon DPT. The number of nucleation sites, directly related to the number of defects and $\mathrm{Nb}$-rich precipitates, is lower in case of ST1050 condition compared to ST1010 condition, thereby minimizing the number of intragranular $\delta$-precipitates.

\subsubsection{Influence of $\delta$-phase morphology}

The performance of alloy 718 depends on the variation in morphology of $\delta$-phase under different treatment conditions. The intergranular $\delta$-precipitation noticed on short-term 


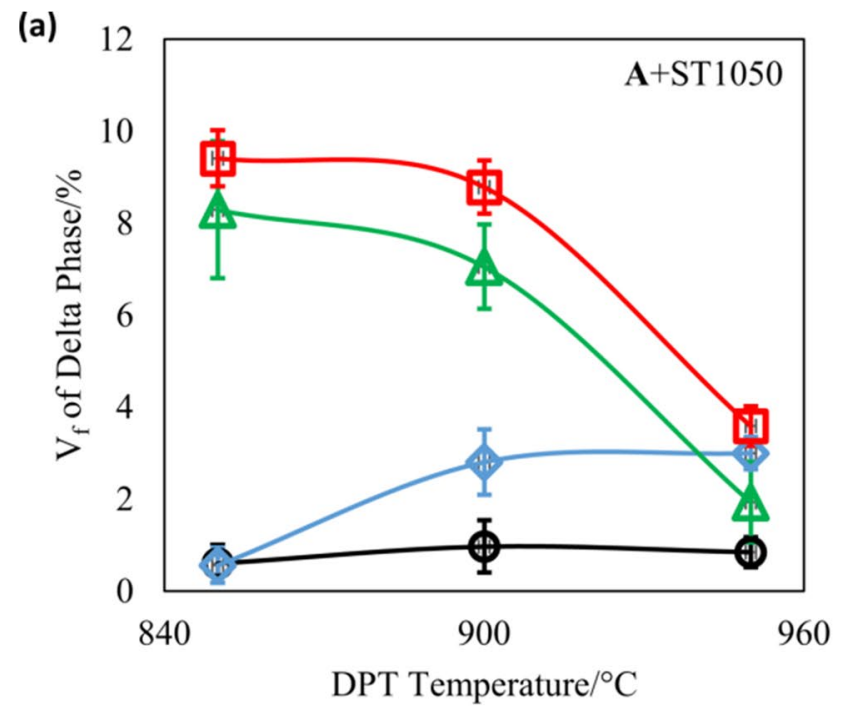

-A-1hr $-\mathrm{A}-8 \mathrm{hr}-\mathrm{A}-24 \mathrm{hr} \in \mathrm{A}-48 \mathrm{hr}$

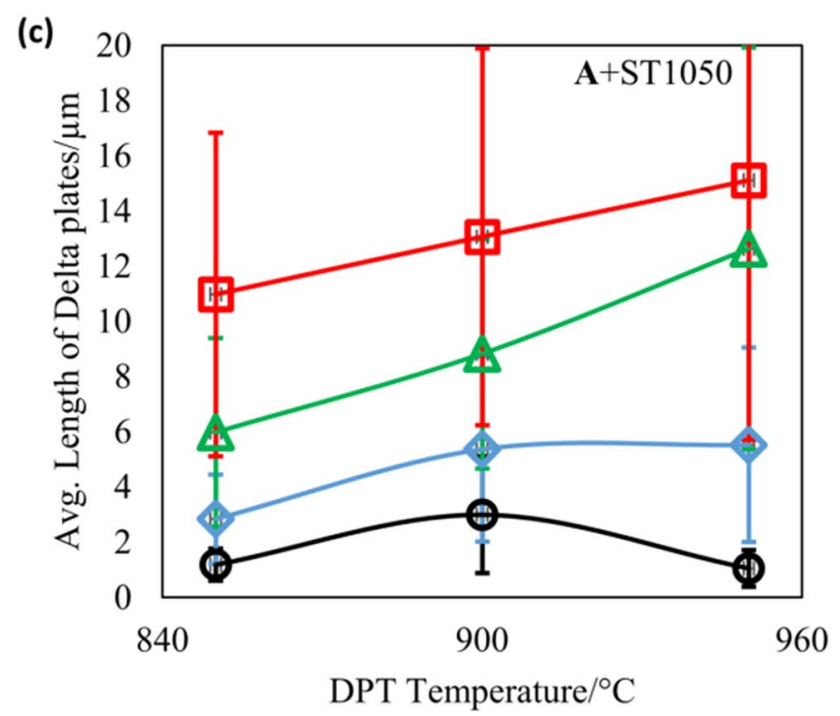

-A-1h $-\mathrm{A}-8 \mathrm{~h}-\mathrm{A}-24 \mathrm{~h}-\mathrm{A}-48 \mathrm{~h}$

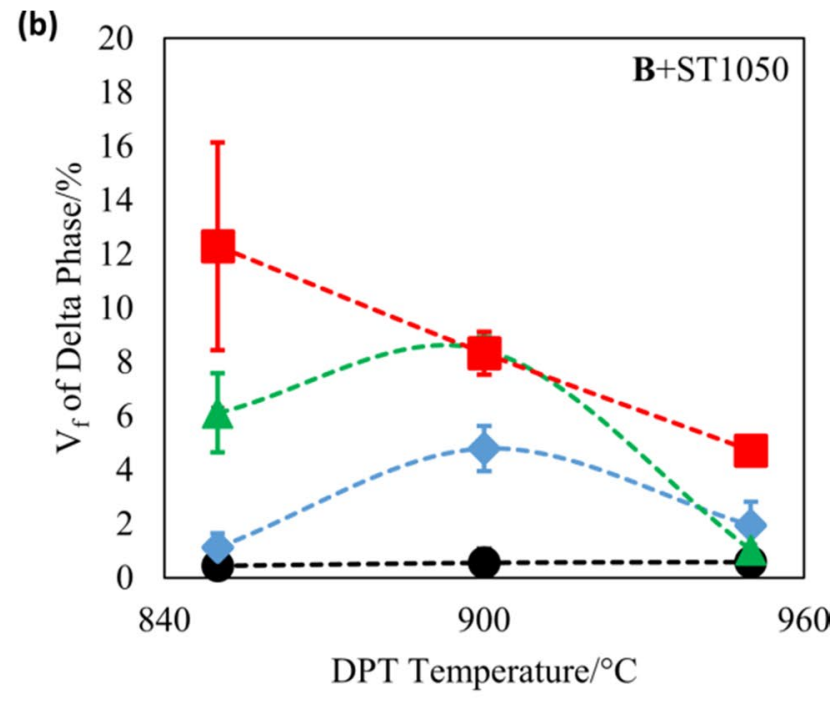

B-1hr - - B-8hr -- - B-24hr - - - B-48hr

(d)

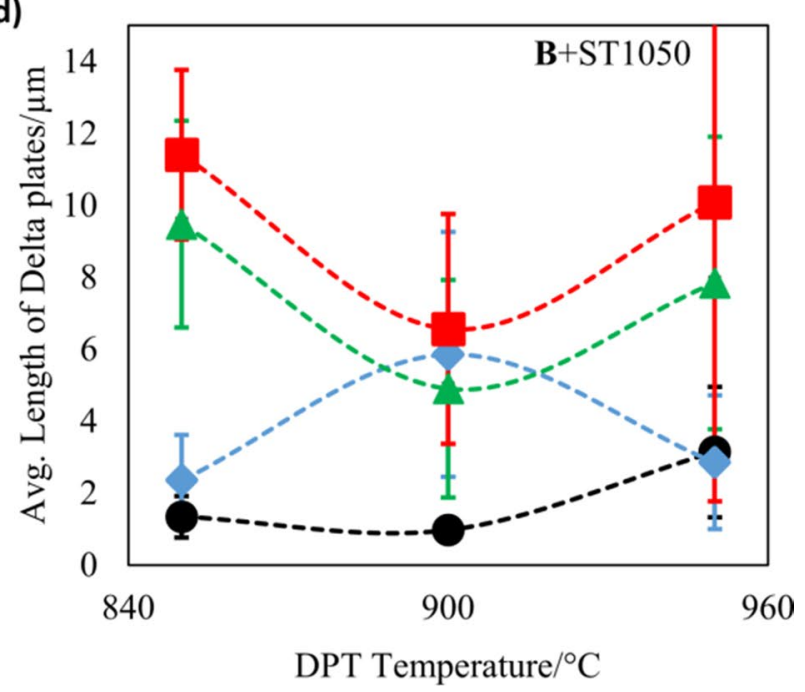

$-\frown--B-1 h-\frown--B-8 h--A--B-24 h----B-48 h$

Fig. 9 Analysis of $\delta$-phase volume fraction in specimen $\mathbf{a} \mathbf{A}, \mathbf{b} \mathbf{B}$; and $\delta$-precipitate length in specimen $\mathbf{c}$ A, d B; subjected to ST1050 and DPT protocols

DPT of solution-treated specimens is known to have beneficial effects on tensile strength, ductility, and stressrupture properties [13, 42]. Fatigue strength and resistance to creep are shown to be unaffected by intragranular $\delta$-precipitation obtained by long-term exposure (8-48 h) under DPT conditions [13]; however, the material ductility is affected adversely. Due to a poor misfit between the matrix and $\delta$-precipitates, the intragranular delta provides sites for void nucleation and crack propagation. Also, the fragmentation and coalescence of micro-voids are shown to affect the material ductility upon subjecting material to DPT [41]. Contrarily, a weldability analysis performed through thermomechanical simulation shows that grain size is the main cause of decrease in ductility in alloy 718 specimens having varied amount of $\delta$-phase precipitates upon subjecting the material to high temperatures. The researchers subjected wrought form of alloy 718 to varied solution treatment and DPT protocols with heating-cooling rates of $111^{\circ} \mathrm{C} / \mathrm{s}$ and $50{ }^{\circ} \mathrm{C} / \mathrm{s}$, respectively. The specimen subjected to $954{ }^{\circ} \mathrm{C} / 15 \mathrm{~h}$ treatment which had the highest amount of $\delta$-phase showed better ductility compared to other counterparts as per the study of Andersson et al. [43]. However, 
specimen subjected to $1050{ }^{\circ} \mathrm{C} / 3 \mathrm{~h}+954{ }^{\circ} \mathrm{C} / 1 \mathrm{~h}$ treatment which evidently showed no $\delta$-precipitation which leads to grain growth and thereby proved to be least ductile material. Therefore, long-term exposure of alloy 718 to DPT temperatures during repair activities might call for reconditioning of the material to eliminate the excess amounts of intragranular $\delta$-phase.

\section{Conclusions}

The effect of heat treatments on $\delta$-precipitation characteristics for DED specimens is studied in this article. The conditions for varied $\delta$-morphologies are revealed, and an effort is made to correlate the properties that can be expected in different scenarios of $\delta$-precipitation. A few salient features of this study are as follows:

1. The initial as-built condition had varied microstructural features due to the processing conditions, including differences in grain size and segregation behavior. However, these variations had little effect on precipitation of $\delta$-phase as both specimens with different DED conditions showed similar volume fractions and lengths of interdendritic $\delta$-phase precipitation when subjected to direct delta processing treatment.

2. An intermediate solution treatment performed either at $1010{ }^{\circ} \mathrm{C}$ or at $1050{ }^{\circ} \mathrm{C}$ resulted in dissolution of most of the $\mathrm{Nb}$-rich precipitates and induced grain growth in the material. Furthermore, the grains recrystallized more notably at the higher solution treatment temperature of $1050{ }^{\circ} \mathrm{C}$.

3. Specimens subjected to solution treatment and delta processing treatment for short-term exposures showed low volume fractions of intergranular $\delta$-phase precipitates. For long-term exposures, intragranular $\delta$-precipitates were predominantly seen for specimens solution treated at $1010{ }^{\circ} \mathrm{C}$, and both inter- and intragranular $\delta$-precipitates were formed for specimens solution treated at $1050{ }^{\circ} \mathrm{C}$.

4. The length scale of $\delta$-precipitates was highest in case of specimens solution treated at $1050{ }^{\circ} \mathrm{C}$ followed by $1010{ }^{\circ} \mathrm{C}$ solution treatment, while as-built condition showed the shortest $\delta$-precipitates. Intergranular precipitation of long-striped $\delta$-plates was noted on long-term exposure of delta processed specimens solution treated at $1050{ }^{\circ} \mathrm{C}$

Acknowledgements The authors would like to thank the support of project partners in GKN Aerospace AB and Sandvik Material Technologies for their timely advisory and continual support throughout the tenure for this research.
Author contribution SS: conceptualization, investigation, methodology, analysis, and writing - original draft. KH: methodology, experimentation, analysis. SJ: conceptualization, data curation, supervision, and writing - review and editing. JA: conceptualization, data curation, supervision, and writing.

Funding The current work is funded by Vinnova, Centre for Additive Manufacture - Metal (CAM2) and Sustainable Manufacturing through Next-Generation Additive Processes (SUMAN-Next) projects. Open Access funding provided by University West.

Code availability Not applicable.

\section{Declarations}

Conflict of interest The authors declare no competing interests.

Open Access This article is licensed under a Creative Commons Attribution 4.0 International License, which permits use, sharing, adaptation, distribution and reproduction in any medium or format, as long as you give appropriate credit to the original author(s) and the source, provide a link to the Creative Commons licence, and indicate if changes were made. The images or other third party material in this article are included in the article's Creative Commons licence, unless indicated otherwise in a credit line to the material. If material is not included in the article's Creative Commons licence and your intended use is not permitted by statutory regulation or exceeds the permitted use, you will need to obtain permission directly from the copyright holder. To view a copy of this licence, visit http://creativecommons.org/licenses/by/4.0/.

\section{References}

1. Sundararaman M, Mukhopadhyay P, Banerjee S (1992) Some aspects of the precipitation of metastable intermetallic phases in Inconel 718. Metall Trans A 23(7):2015-2028. https://doi.org/10. 1007/bf02647549

2. Mahadevan S, Nalawade S, Singh JB, Verma A, Paul B, Ramaswamy K (2010) Evolution of delta phase microstructure in alloy 718. Superalloy 718 and derivatives. https://doi.org/10.1002/ 9781118495223.ch57

3. Brooks JW, Bridges PJ (1988) Metallurgical stability of Inconel alloy 718. In Superalloys 1988 (Sixth International Symposium). 33-42. https://doi.org/10.7449/1988/Superalloys_1988_33_42

4. Zhu Q, Chen G, Wang C, Cheng L, Qin H, Zhang P (2019) Effect of the delta phase on the tensile properties of a nickel-based superalloy. Metals 9(11):1153. https://doi.org/10.3390/met9111153

5. Rao NM (2010) Factors influencing the notch rupture life of superalloy 718. Trans Indian Inst Metals 63(2-3):363-367. https://doi. org/10.1007/s12666-010-0048-3

6. Liu D, Lippold JC, Li J, Rohklin SR, Vollbrecht J, Grylls R (2014) Laser engineered net shape (LENS) technology for the repair of Ni-base superalloy turbine components. Metall Mater Trans A 45(10):4454-4469. https://doi.org/10.1007/s11661-014-2397-8

7. Leino M, Pekkarinen J, Soukka R (2016) The role of laser additive manufacturing methods of metals in repair, refurbishment and remanufacturing - enabling circular economy. Phys Procedia 83:752-760. https://doi.org/10.1016/j.phpro.2016.08.077

8. Anderson M, Thielin AL, Bridier F, Bocher P, Savoie J (2017) Delta phase precipitation in Inconel 718 and associated mechanical properties. Mater Sci Eng A 679:48-55. https://doi.org/10. 1016/j.msea.2016.09.114 
9. Kuo CM, Yang YT, Bor HY, Wei CN, Tai CC (2009) Aging effects on the microstructure and creep behavior of Inconel 718 superalloy. Mater Sci Eng A 510-511:289-294. https://doi.org/ 10.1016/j.msea.2008.04.097

10 Cai D, Zhang W, Nie P, Liu W, Yao M (2007) Dissolution kinetics of delta phase and its influence on the notch sensitivity of Inconel 718. Mater Char 58(3):220-225. https://doi.org/10.1016/j.match ar.2006.04.020

11 Valle LCM, Araújo LS, Gabriel SB, Dille J, de Almeida LH (2012) The effect of delta phase on the mechanical properties of an Inconel 718 superalloy. J Mater Eng Perform 22(5):1512-1518. https://doi.org/10.1007/s11665-012-0433-7

12. Li S, Yang J, Zhuang J, Deng Q, Du J, Xie X, Li B, Xu Z, Cao Z, Su Z, Jiang C (1994) The effect of delta phase on crack propagation under creep and fatigue conditions in alloy 718. In Superalloys 718, 625, 706 and Various Derivatives, pp 545-555. https:// doi.org/10.7449/1994/Superalloys_1994_545_555

13. Desvallees Y, Bouzidi M, Bois F, Beaude N (1994) Delta phase in Inconel 718: mechanical properties and forging process requirements. In Superalloys, pp. 281-291. https://doi.org/10.7449/ 1994\%2FSUPERALLOYS_1994_281_291

14. Zhong C, Biermann T, Gasser A, Poprawe R (2015) Experimental study of effects of main process parameters on porosity, track geometry, deposition rate, and powder efficiency for high deposition rate laser metal deposition. J Laser Appl 27(4):042003. https://doi.org/10.2351/1.4923335

15. Li Y, Hu Y, Cong W, Zhi L, Guo Z (2017) Additive manufacturing of alumina using laser engineered net shaping: effects of deposition variables. Ceram Int 43(10):7768-7775. https://doi.org/10. 1016/j.ceramint.2017.03.085

16. Zhong C, Gasser A, Kittel J, Fu J, Ding Y, Poprawe R (2016) Microstructures and tensile properties of Inconel 718 formed by high deposition-rate laser metal deposition. J Laser Appl 28(2):022010. https://doi.org/10.2351/1.4943290

17. Li Z, Chen J, Sui S, Zhong C, Lu X, Lin X (2020) The microstructure evolution and tensile properties of Inconel 718 fabricated by high-deposition-rate laser directed energy deposition. Addit Manuf 31:100941. https://doi.org/10.1016/j.addma.2019.100941

18 Blackwell PL (2005) The mechanical and microstructural characteristics of laser-deposited IN718. J Mater Proc Technol 170(12):240-246. https://doi.org/10.1016/j.jmatprotec.2005.05.005

19 Oliari SH, Doliveira ASCM, Schulz M (2017) Additive manufacturing of $\mathrm{H} 11$ with wire-based laser metal deposition. Soldagem Inspeção 22(4):466-479. https://doi.org/10.1590/0104-9224/ si2204.06

20. ASTM-International (2013) ASTM E112-13, Standard test methods for determining average grain size. ASTM-International, West Conshohocken. https://doi.org/10.1520/E0112-13

21. Tien JK, Caulfield T (1989) Superalloys supercomposites superceramics. Philips Laboratories, Briarcliff Manor. https://doi.org/ 10.1016/c2012-0-01671-7

22. Karimi P, Sadeghi E, Åkerfeldt P, Ålgårdh J, Andersson J (2018) Influence of successive thermal cycling on microstructure evolution of EBM-manufactured alloy 718 in track-by-track and layer-by-layer design. Mater Des 160:427-441. https://doi.org/ 10.1016/j.matdes.2018.09.038

23. Patel AD, Murty YV (2001) Effect of cooling rate on microstructural development in alloy 718. In Superalloys 718, 625, 706 and Various Derivatives, pp. 123-132. https://doi.org/10.7449/2001/ Superalloys_2001_123_132

24. Nie P, Ojo OA, Li Z (2014) Modeling analysis of laser cladding of a nickel-based superalloy. Surf Coat Technol 258:1048-1059. https://doi.org/10.1016/j.surfcoat.2014.07.030

25. Sreekanth S, Ghassemali E, Hurtig K, Joshi S, Andersson J (2020) Effect of direct energy deposition process parameters on single-track deposits of alloy 718. Metals 10(1):96. https://doi. org/10.3390/met10010096

26. Sreekanth S, Hurtig K, Joshi S, Andersson J (2021) Influence of laser-directed energy deposition process parameters and thermal post-treatments on $\mathrm{Nb}$-rich secondary phases in single-track alloy 718 specimens. J Laser Appl 33(2):022024. https://doi.org/ 10.2351/7.0000259

27. Ling LS, Yin Z, Hu Z, Liang JH, Wang ZY, Wang J, Sun BD (2019) Effects of the gamma double prime- $\mathrm{Ni}_{3} \mathrm{Nb}$ phase on mechanical properties of Inconel 718 superalloys with different heat treatments. Materials (Basel). 13(1):151. https://doi.org/10. 3390/ma13010151

28. Nie P, Ojo OA, Li Z (2014) Numerical modeling of microstructure evolution during laser additive manufacturing of a nickel-based superalloy. Acta Mater 77:85-95. https://doi.org/10.1016/j.actam at.2014.05.039

29. Ma M, Wang Z, Zeng X (2015) Effect of energy input on microstructural evolution of direct laser fabricated IN718 alloy. Mater Charact 106:420-427. https://doi.org/10.1016/j.matchar.2015.06. 027

30. Chen Y, Guo Y, Xu M, Ma C, Zhang Q, Wang L, Yao J, Li Z (2019) Study on the element segregation and Laves phase formation in the laser metal deposited IN718 superalloy by flat top laser and gaussian distribution laser. Mater Sci Eng, A 754:339-347. https://doi.org/10.1016/j.msea.2019.03.096

31. Mankins W, Lampman S (2016) Heat treatment of wrought nickel alloys. In: Totten GE (ed) Heat Treating of Nonferrous Alloys. ASM International, Netherlands, pp 426-458. https://doi.org/10. 31399/asm.hb.v04e.a0006265

32. DuPont JN, Lippold JC, Kiser SD (2009) Welding metallurgy and weldability of nickel-base alloys. https://doi.org/10.1002/97804 70500262

33. Cao J, Liu F, Lin X, Huang C, Chen J, Huang W (2013) Effect of overlap rate on recrystallization behaviors of laser solid formed Inconel 718 superalloy. Opt Laser Technol 45:228-235. https:// doi.org/10.1016/j.optlastec.2012.06.043

34. Li Z, Zhang L, Sun N, Sun Y, Shan A (2014) Effects of prior deformation and annealing process on microstructure and annealing twin density in a nickel based alloy. Mater Charact 95:299_ 306. https://doi.org/10.1016/j.matchar.2014.07.013

35. Smith DH, Bicknell J, Jorgensen L, Patterson BM, Cordes NL, Tsukrov I, Knezevic M (2016) Microstructure and mechanical behavior of direct metal laser sintered Inconel alloy 718. Mater Charact 113:1-9. https://doi.org/10.1016/j.matchar.2016.01.003

36. Li X, Shi JJ, Cao GH, Russell AM, Zhou ZJ, Li CP, Chen GF (2019) Improved plasticity of Inconel 718 superalloy fabricated by selective laser melting through a novel heat treatment process. Mater Design 180:107915. https://doi.org/10.1016/j.matdes.2019.107915

37. Ram GDJ, Reddy AV, Rao KP, Reddy GM (2013) Control of Laves phase in Inconel 718 GTA welds with current pulsing. Sci Technol Weld Join 9(5):390-398. https://doi.org/10.1179/13621 7104225021788

38 Ram GDJ, Reddy AV, Rao KP, Reddy GM, Sundar JKS (2005) Microstructure and tensile properties of Inconel 718 pulsed NdYAG laser welds. J Mater Proc Technol 167(1):73-82. https://doi. org/10.1016/j.jmatprotec.2004.09.081

39 Azadian S, Wei LY, Warren R (2004) Delta phase precipitation in Inconel 718. Mater Char 53(1):7-16. https://doi.org/10.1016/j. matchar.2004.07.004

40. Kuo YL, Horikawa S, Kakehi K (2017) The effect of interdendritic delta phase on the mechanical properties of alloy 718 built up by additive manufacturing. Mater Des 116:411-418. https://doi.org/ 10.1016/j.matdes.2016.12.026

41. Sui S, Chen J, Ma L, Fan W, Tan H, Liu F, Lin X (2019) Microstructures and stress rupture properties of pulse laser repaired Inconel 718 superalloy after different heat treatments. J Alloy 
Compd 770:125-135. https://doi.org/10.1016/j.jallcom.2018.08. 063

42. Muller JF, Donachie MJ (1975) The effects of solution and intermediate heat treatments on the notch-rupture behavior of Inconel 718. Metall Trans A 6(12):2221. https://doi.org/10.1007/bf02818647

43. Andersson J, Sjöberg GP, Viskari L, Chaturvedi MC (2013) Effect of solution heat treatments on superalloys part 1 - alloy 718. Mater Sci Technol 28(5):609-619. https://doi.org/10.1179/ 1743284711y.0000000101
Publisher's Note Springer Nature remains neutral with regard to jurisdictional claims in published maps and institutional affiliations. 